\title{
“NESSE TEMPO NÃO EXISTIA ESSAS ILHAS POR ALI": SOBRE MODOS DE PERCEBER O AMBIENTE E NARRAR O PASSADO.
}

\author{
Edna F. Alencar ${ }^{1}$
}

\section{Introdução}

Nas áreas de várzea ${ }^{2}$ da região do médio rio Solimões a sazonalidade causada pela oscilação do nível das águas dos rios imprime uma dinâmica especial à vida dos moradores, que recorrem a várias estratégias para interagir com esse tipo de ambiente. Na estação seca, ou verão, os rios atingem o nível mais baixo, e na estação das chuvas ou inverno, quando ocorre a cheia dos rios, o pulso da inundação chega a atingir 15 metros e as águas cobrem os terrenos mais altos (SCM/MCT-CNPq, 1996; Ayres, 1996). Uma característica das várzeas dessa região é o processo de transformação das paisagens que é estimulado, por um lado, pela agência das pessoas ao interagir com o ambiente usando tecnologias para a construção de casas, para a abertura de roças de mandioca e de banana, ou fazer campos de pastagem para o gado e cultivar espécies de plantas não nativas; e por outro lado, pela agência da própria natureza, a partir de dois fenômenos opostos: a terra caída e a formação de praias, de terras novas. Esses fenômenos estão associados às fortes correntezas do rio Solimões que movimentam enormes dunas de areia, e estas ao se acumularem em determinados pontos do seu leito formam extensas praias que são visíveis no período da seca. Aos poucos essas praias são colonizadas por uma vegetação típica desse ambiente e que ajuda a fixar os sedimentos que são carreados pelas aguas. À medida que a vegetação cresce, mais sedimentos são acumulados e, em poucos anos, essas praias tornam-se ilhas (Ayres, 1996; SCM 1996; Alencar, 2002). Esse processo de formação e destruição dos terrenos, que ocorre num espaço de tempo muito curto e pode ser perceptível de um ano para outro (Alencar, 2002), altera as paisagens da várzea e provoca a mobilidade constante das casas e dos povoados. Nas áreas mais instáveis os moradores são obrigados a desfazer

\footnotetext{
${ }^{1}$ Universidade Federal do Pará, Brasil.

${ }^{2}$ As várzeas ocupam uma área de cerca de 1,5\% de toda planície Amazônica e apresentam grande concentração de biodiversidade. Em território brasileiro a várzea possui uma extensão de cerca de $65 \mathrm{mil} \mathrm{km}^{2}$ (Porro, 1995), e uma largura que varia de $25 \mathrm{~km}$ na parte mais estreita, e 200 quilômetros na parte mais larga (Ayres, 1996).
} 
suas casas e reconstruí-las em outro local ${ }^{3}$ sempre que as terras caem ou surgem praias que isolam os povoados.

As estratégias desenvolvidas pelas populações locais para interagir com este tipo de ambiente, presentes na forma de uso do solo para atividades agrícolas, de apropriação dos recursos naturais e na mobilidade sazonal, fazem parte de um corpo de conhecimentos sobre o ambiente, e expressam atitudes práticas e simbólicas que caracterizam seu modo de vida. Elas expressam formas particulares de vivenciar e experienciar o mundo, não só o mundo que pode ser concretamente observado, em sua materialidade, mas também o mundo sensível, e cujo conhecimento ajuda a entender sua visão de mundo, seu modo de estar no mundo (Alencar, 2002, Silveira, 2009).

Neste artigo procuro analisar as estratégias utilizadas pelos moradores da comunidade São João, localizada na ilha do São João, dentro da Reserva de Desenvolvimento Sustentável Mamirauá (RDSM) ${ }^{4}$, para habitar esse tipo de ambiente. Ao longo de um século esses moradores vem se deslocando numa paisagem em permanente transformação, causada pelas fortes correntezas do rio Solimões que destroem os terrenos e fazem surgir outros elementos da paisagem, como as praias, as ilhas, os lagos e as ressacas. A cada ano, as pessoas mudam suas casas de lugar, roças são destruídas, povoados deixam de existir, e algumas referências espaciais usadas para se situar na paisagem são alteradas. O objetivo é compreender o modo como elas interagem com esse tipo de ambiente, como lidam com as transformações, e quais as percepções e representações que constroem sobre uma paisagem que é destruída e refeita em curto espaço de tempo; e as estratégias utilizadas para conservar os vínculos com o lugar de seus antepassados e se manter enquanto um grupo social. Para isso, precisamos entender qual a concepção de lugar, considerando-se que determinados elementos da paisagem que funcionariam como ancoras de reforço da memoria social sobre o lugar são destruídos, tornando mais complexo o exercício de situar na paisagem os eventos que fazem parte da história do grupo. Especialmente quando não se

\footnotetext{
${ }^{3}$ Esse fenômeno tem sido mencionado por missionários e viajantes que percorreram essa região desde o século XVII, e descreveram o processo de ocupação humana (Bates, 1989), e apontaram algumas características do ambiente de várzea e comportamento das populações humanas, e que podem ser verificados até o presente (Alencar, 2002; Alencar e Sousa, 2012).

${ }^{4}$ A Reserva de Desenvolvimento Sustentável Mamirauá é uma unidade de conservação criada pelo governo do estado do Amazonas, que admite a presença humana e o uso direto dos recursos naturais. Abrange a maior área de florestas inundadas do Brasil, com uma área de 1.124.000 ha (Ayres, J. M., Moura, E. \& Lima-Ayres, D., 1992; SCM/MCT-CNPq, 1996).
} 
consegue apontar nas paisagens as trilhas traçadas pelos ancestrais que abriram o lugar e ai inscreveram sua geografia de mundo (Pietrafesa de Godoi, 1999). Portanto, compreender o sentido que é dado à noção de lugar torna-se central para conhecer a identidade desse grupo, e quais os vínculos entre as gerações são conservados.

Meu primeiro contato com os moradores do povoado São João ocorreu em março de 1993, quando realizei uma pesquisa com o objetivo de conhecer o processo de ocupação humana de uma área especifica da Reserva Mamirauá ${ }^{5}$. Era o período do inverno amazônico, quando as aguas do rio Solimões invadem as terras e transformam as áreas de várzea num imenso lago, muitas vezes atingindo as moradias dos ribeirinhos. Na ocasião pude verificar a destruição dos terrenos situados às margens do rio Solimões pelo fenômeno da terra caída, que avançava sobre as casas situadas na Ilha do São João ${ }^{6}$. Retornei ao povoado em outubro desse mesmo ano, no período do verão, quando as aguas estavam no nível mais baixo, e um fato me chamou a atenção na paisagem desta comunidade: a existência de um barranco muito alto na parte da ilha que estava voltada para o rio Solimões, ficando assim gravada nos "olhos da mente" a imagem de uma pequena casa de madeira, construída sobre palafitas, à beira do barranco e, próximo a ela, havia um cemitério onde estavam enterrados alguns dos primeiros fundadores do lugar ${ }^{7}$.

Retornei ao São João uma terceira vez, no verão de 2000, com o propósito de realizar a pesquisa de campo do meu projeto de tese de doutoramento (Alencar, 2002) ${ }^{8}$. Nesse momento os moradores conviviam, de forma muito intensa, com novas ameaças de terra caída, e algumas famílias estavam se preparando para realizar mais uma mudança de suas moradias. Quando retornei no verão deste mesmo ano, não mais encontrei a casa na qual havia me hospedado durante a etapa de pesquisa de campo realizada no inverno, pois a terra caída havia destruído o terreno, e a família desfez a casa para reconstruí-la em outro local mais distante das margens do rio, e de tamanho menor que a anterior. Diante desse fato precisei buscar outro local para morar. Como a maioria das casas do povoado eram

\footnotetext{
${ }^{5}$ Para informações sobre os resultados da pesquisa, encaminho o leitor aos artigos de Lima, Deborah de M. \& Alencar, Edna F. 2000; Lima, Deborah de M. \& Alencar, Edna F. 2001; e Alencar 2010.

${ }^{6}$ Esta ilha é banhada em parte pelo rio Solimões e, em parte, pelo paraná do São João, um curso de agua que separa a ilha do São João de outra ilha conhecida como ilha do Pão.

${ }^{7}$ Anos mais tarde, quando retornei, o cemitério havia sido destruído pela terra caída. E os restos mortais dos que ali estavam enterrados jaziam agora em algum lugar do profundo leito do rio Solimões.

${ }^{8}$ A pesquisa contou com o apoio financeiro da Sociedade Civil Mamirauá (SCM) e do Instituto de Desenvolvimento Sustentável Mamirauá - IDSM/MCT.
}

Iluminuras, Porto Alegre, v. 14, n. 34, p. 11-32, ago./dez. 2013 
pequenas e abrigavam famílias numerosas, e estavam na iminência de serem destruídas pela terra caída, pude vivenciar durante os seis meses que permaneci em campo a expectativa dessas famílias, a cada chuva intensa, sempre atentas aos sinais de desmoronamento dos terrenos das margens do rio.

Em agosto de 2011 retornei ao São João para entregar um livro contendo a história do povoado, resultado das pesquisas realizadas anteriormente (Alencar, 2010), e nesse momento me deparei com uma nova paisagem, como ocorreu nas outras viagens. Agora as casas já estavam sendo construídas no local onde estavam as capoeiras dos antigos, e que antes serviam como ancoras da memoria social do grupo para situar o lugar que fora aberto pelos antigos (Alencar, 2002), e outras foram construídas sobre grossos troncos de madeira, da árvore de assacu (Hura crepitans L) que possui madeira leve, num tipo de construção que regionalmente recebe o nome de flutuante. A reconfiguração da paisagem física, onde agora predominavam as casas flutuantes, também gerou uma reconfiguração da paisagem de parentesco, uma vez que novas famílias haviam sido formadas, e construíram suas casas em determinados espaços, e uma nova geração de moradores havia surgido. Ao percorrer o pequeno povoado precisei da ajuda de moradores mais velhos para me situar na paisagem do presente e, para isso, eles tiveram que me situar inicialmente na paisagem do passado. Ou seja, precisei recordar onde estavam as casas das pessoas que eu havia conhecido, para entender as mudanças que haviam se processado na paisagem, e tudo isso sem ter a materialidade da paisagem do passado, pois a terra havia desaparecido e, junto com ela, as casas, as árvores que eram as toponímias a partir das quais eu me situava nessa paisagem. Assim, no tempo de duas décadas, pude testemunhar a mobilidade constante realizada pelas famílias do São João, à medida que as terras situadas às margens do rio eram destruídas. O espaço da ilha havia sido reduzido significativamente, e restava apenas uma estreita faixa de terras mais altas onde estavam localizadas as casas, e estas já estavam sendo construídas próximas às moradias de famílias que residiam em povoados vizinhos, ocupando parte de seus territórios. No entanto, os moradores deixavam evidentes em suas falas que ainda se sentiam como morando afetivamente no lugar que foi construído pelos ancestrais.

Para quem sai de um ambiente de terra firme, o encontro com esta região da várzea amazônica, com suas vastas planícies alagadas durante o inverno, que se alternam à floresta densa, e com alterações constantes no leito do rio principal, gera muitas surpresas e 
perguntas. Que tipo de relação essa população mantem com este ambiente marcado por eventos cíclicos, e outros imprevisíveis, mas já esperados, que geram perdas materiais e fazem desaparecer as terras? Quais as estratégias usadas para se situar nessa paisagem em permanente transformação, e como percebem essas transformações? Quais elementos da paisagem são selecionados e tornados constitutivos da memória do lugar, e tornados lugar de memória (Nora, 1997), como um patrimônio que é repassado às novas gerações, e reforça a história desse grupo? E que é importante e necessário para estabelecer e reforçar o vinculo intergeracional com o lugar aberto pelos ancestrais?

A análise está baseada em material etnográfico, narrativas coletadas junto aos moradores do São João que pertencem a diferentes gerações ${ }^{9}$, e contem relatos de eventos que ocorreram no lugar, sobre as ações dos antepassados, e servem para expressar suas percepções sobre o ambiente, e as transformações que observam nas paisagens. Em vários momentos é possível observar que os narradores reproduzem, em suas falas, fragmentos de narrativas que ouviram de seus pais, ou de avós, e que são, por sua vez, fragmentos da história das primeiras gerações que formaram o lugar e o grupo social; elas também contem informações relevantes sobre a história ambiental da região. Ao reproduzir essas narrativas as gerações do presente reforçam a história da origem do lugar, da identidade do grupo com a terra. Contudo, eles se deparam com o desafio de ancorar na paisagem do presente os eventos narrados, de apontar os monumentos que formam o patrimônio cultural e que ligariam as gerações do presente ao passado, e ao seu futuro (Gonçalves, 2005).

\section{Ocupar o espaço e abrir o lugar: “...nesse tempo não tinha essas ilhas por ali...”}

Nas primeiras décadas do século XX vários povoados foram formados na região do médio Solimões e dentre eles está o povoado São Pedro, que depois foi renomeado como São João, formado nos anos 30 do século XX por João Ramos e Maria Torcata Nunes, que nasceram no povoado peruano de Cavalo Cocho, localizado próximo à fronteira do Peru com o Brasil (Alencar, 2002). Em sua trajetória migratória dentro da região do médio rio Solimões, esta família seguiu o percurso realizado por outras famílias que estavam

\footnotetext{
${ }^{9}$ As narrativas fazem parte do material etnográfico coletado durante pesquisa realizada como parte do projeto para elaboração de minha tese de doutorado (ver Alencar 2002 e Alencar 2010). As informações foram atualizadas com observações realizadas em agosto de 2011.
}

Iluminuras, Porto Alegre, v. 14, n. 34, p. 11-32, ago./dez. 2013 
migrando de áreas de seringais situadas nas cabeceiras dos rios Juruá, Içá, Jutaí, e do AuatíParanã $^{10}$, (Lima-Ayres, 1992; Lima \& Alencar, 2000 e 2001; Alencar, 2002). Eles pararam inicialmente no povoado Tomé, situado no Auati-Paraná onde fixaram residência por alguns anos, e estabeleceram alianças com a família de Manoel Pedro Morais cuja filha Maria Eduarda Morais casou-se com o Fortunato Ramos, filho de João e Torcata. No inicio da década de 1930, João Ramos e Maria Torcata, acompanhados dos filhos, migraram para a cidade de Tefé, onde residia uma irmã de João Ramos (Alencar, 2010). Partia em busca de trabalho, mas no percurso de descida do rio Solimões eles decidiram parar num povoado de nome Bonsucesso, para descansar e conseguir alimentos. Meses, ou anos, depois, decidiram fixar residência na região fundando o povoado São Pedro (Alencar, 2002; Alencar 2010).

Quando eles baixaram, ficaram um tempo no Bonsucesso e, depois, foram pra Macoapani, que era um povoado grande nessa época. Eles iam pra Tefé, iam de muda. Aí foi o tempo que eles pararam lá na casa desse patrão, seu Manoel Rola, que era uma casa de comércio. Aí o velho perguntou se eles queriam trabalhar pra ele. Nesse tempo isso aqui era muito farto, tinha muita produção. Aí foi o tempo que ele conheceu esse lugar aqui [onde está o São João]. Não morava ninguém nessa terra. O pessoal que tinha morado ali onde é aquele pãozeiro, já tinha saído. [...] Nesse tempo não tinha essas ilhas por ali [margem oposta do Solimões]. A terra já pegava já do outro lado, pra banda da restinga do Macoapani. O rio era só um. Essa terra era devoluta, não tinha dono. Aí vieram já morar pra cá, pra essa ponta de terra. Mas não era aqui não. Era numa ponta de terra que ficava lá muito em cima! [...] Aí eles já formaram esse povoado [...]. Era grande, tinha umas vinte e tantas casas. (Sr. A. M. Ramos ${ }^{11}, 65$ anos, comunidade de São João, maio de 2001).

A memória desse momento de fundação do lugar por João Ramos será conservada pelos mais antigos e repassada ao longo das gerações, para construir e reforçar a identidade social do grupo, e o pertencimento a um grupo de parentesco. Ela busca recuperar o momento fundante do grupo de parentesco e do grupo social, quando os antepassados "limparam" a terra, derrubaram a mata e construíram as primeiras casas, ou seja, abriram o lugar. Aqui observamos que a ausência da casa, de acordo com Gaston Bachelard (1993)

\footnotetext{
${ }^{10}$ Curso de água que liga o rio Solimões ao rio Japurá, e forma um dos limites da RDS Mamirauá. O AuatiParaná foi muito usado como via de acesso ao baixo rio Japurá, por migrantes que desciam dos seringais do alto Solimões.

${ }^{11} \mathrm{O}$ Sr. A. Morais Ramos é neto do fundador do povoado, João Ramos. A época da entrevista ele tinha 65 anos. A entrevista foi realizada em sua casa, no mês de maio de 2001. Em 2011 ele ainda morava no povoado, mas em uma casa flutuante.
}

Iluminuras, Porto Alegre, v. 14, n. 34, p. 11-32, ago./dez. 2013 
seria a própria ausência de vida, o abandono, ou seja, a "não-ocupação", pois todo espaço realmente habitado traz em sua essência a noção de casa (Bachelard, 1993).

O abrir o lugar refere-se ao processo onde um grupo social se vincula a um espaço e, a partir dele, interage com outros organismos, elaborando modelos socioculturais que orientam a forma como seus membros vão interagir com o ambiente (Mauss, 1974). O lugar é o espaço significado, construído socialmente pelas atividades práticas que as pessoas desenvolvem ao interagir com o ambiente, ou seja, é o "espaço criador de identidades e de relações sociais num tempo e espaço definidos" (Augé, 2012: 47). Ao interagir com o ambiente as pessoas criam categorias para classificar os diferentes elementos da natureza que lhes são perceptíveis, atribuindo significados a cada um deles, num processo que envolve a dimensão do visível e também do sensível (Ingold, 2000). O ato de classificar é também uma forma de expressar uma visão de mundo, de atribuir "personalidade ao espaço e, consequentemente, transformando o espaço em lugar” (Tuan, 1983: 103). Portanto, o lugar São João refere-se ao espaço que foi significado, e comprova a agencia das primeiras gerações da família Ramos ao construir as primeiras casas, fazer os primeiros roçados, e cultivar plantas frutíferas - mangueiras, coqueiros, limoeiros, e laranjeiras -, espécies não nativas da várzea ${ }^{12}$. No processo de construção simbólica do espaço os moradores de São João utilizam certas referencias espaciais e cognitivas, sustentam sua identidade (Mauss, 1974; Augé, 2012) e reforçam o pertencimento a um grupo de parentesco, a uma ordem social instaurada por um herói fundador (Pietrafesa de Godoi, 1999). O lugar é, ao mesmo tempo, a representação daqueles que o habitam, e a representação para aqueles que estão de fora, ou seja, de "quem o observa" (Augé, 2012: 46).

Apesar de não existir a terra e as casas que abrigaram os primeiros moradores, e não existirem algumas evidências materiais que sirvam de suporte para ancorar a memória dos eventos que ocorreram neste momento fundacional, pois onde antes era terra, e onde foram construídas as primeiras casas, hoje é o leito do rio Solimões, o lugar permanece vivo na memória que é conservada ao longo de gerações. Para Pietrafesa de Godói (1999) "essa memória passa a atuar como criadora de solidariedade, produtora de identidade e portadora

\footnotetext{
${ }^{12}$ A vinculação de uma família com um lugar fica evidente quando as pessoas referem a um povoado como sendo "o lugar desses Braga", ou "o lugar dessa gente de Ramos".
}

Iluminuras, Porto Alegre, v. 14, n. 34, p. 11-32, ago./dez. 2013 
de imaginário, erigindo regras de pertencimento e exclusão que delimitam as fronteiras sociais do grupo" (Pietrafesa de Godói 1999: 15).

Esta realidade contrasta com aquela vivida por grupos sociais situados numa paisagem geográfica estável e que conservam os elementos que são significativos para reforçar os quadros sociais da memória (Halbwachs, 1990), sendo possível identificar os vestígios das ações humanas ao percorrer as trilhas construídas pelos antepassados, ao visitar os lugares onde eles construíram roças e casas; e ocorreram eventos históricos e sociais importantes ${ }^{13}$. Enfim, identificar os monumentos que formam o patrimônio cultural do grupo (Gonçalves, 2005). Nesses contextos, a paisagem material que é perceptível serve como uma moldura que situa a temporalidade das lembranças, reforça a relação entre memória e o lugar, e faz a articulação de espaços simbólicos e culturais nos quais a memória do passado é o suporte, ou a âncora (Woortmann, 1990) para pensar uma situação do presente (Alencar 2002 e 2007). No São João as âncoras desta memória, ou os lugares de memória, são as antigas ilhas destruídas pela terra caída, as praias que viraram ilhas, o rio verdadeiro que teve seu curso alterado e que hoje corre por onde antes havia terra, as roças, as capoeiras e as plantas cultivadas pelos antigos.

Observa-se assim que lugar e a paisagem são dois conceitos centrais para entender o modo de habitar esse universo da várzea, e a memória social tem um papel importante na conservação das imagens que dão vida, e tornam presentes no tempo, as paisagens do passado, ajudando a compreender as paisagens do presente e reforçando o vinculo com o lugar. Se considerarmos que a paisagem existe a partir das percepções e representações que são resultados da interação das sociedades com seus ambientes, a paisagem refere-se a um processo cultural, enquanto "um fenômeno oriundo da experiência humana no mundo" (Silveira, 2009: 73) e sua base é, ao mesmo tempo, material e cognitiva, e seus significados variam de acordo com os diferentes contextos onde são engendrados. A partir da etnografia utilizada neste artigo, tomamos a paisagem como expressão das diferentes formas de engajamento no mundo, e que resulta de um processo cultural, que é simétrico, na medida em que incorpora a dimensão material e a cognitiva (Ingold, 2000). Nesse sentido, ao falarmos de construção e transformação das paisagens estamos nos referindo tanto à

\footnotetext{
${ }^{13}$ Ver trabalhos de Renato Rosaldo (1980), Ecléa Bosi (1993), Vine Delória Jr. (1994), Peter Gow (1995), Simon Schama (1996).
}

Iluminuras, Porto Alegre, v. 14, n. 34, p. 11-32, ago./dez. 2013 
atividade do próprio ambiente, quanto aos processos sociais que "dão forma ao ambiente, ao mesmo tempo que constituem e modificam os lugares e os modos de habitar" (Steil e Carvalho, 2012: 37).

Para compreender o modo como os moradores de São João lidam com as transformações no ambiente que alteram radicalmente a configuração das paisagens do lugar que foi construído por seus antepassados, é necessário conhecer as percepções sobre o ambiente, e as formas como conservam suas memórias.

\section{Sobre modos de perceber o ambiente e de narrar as transformações nas paisagens e no lugar}

Tenho procurado mostrar que as narrativas são o principal meio de acesso ao modo como as pessoas percebem o ambiente e o processo de transformação das paisagens e do lugar, e de compreender a relação que a geração atual mantem com o lugar ancestral, apesar da constante mobilidade das casas e do povoado, e das paisagens destruídas. Portanto, os narradores ao contar e recontar a história do lugar e das transformações nas paisagens, reforçam as referencias espaciais necessárias para que as novas gerações possam se situar na paisagem do presente, e no lugar. A memoria social repassada pelas narrativas garante às novas gerações do São João o acesso a um conjunto de estratégias criadas pelos ancestrais, por meio de atividades práticas, para garantir sua subsistência.

As narrativas tem uma dupla função. Por um lado elas transmitem a história de surgimento do grupo social, ajudando a reforçar vínculos com o lugar do passado, a situar as gerações do presente num lugar que existe enquanto lembrança, uma vez que a materialidade do lugar primordial não pode ser comprovada na paisagem do presente, pois já se acabou tudo. Por outro lado, elas permitem que o grupo repasse experiências que expressam formas socialmente elaboradas e culturalmente estabelecidas de interagir com o ambiente de várzea, e que fazem parte de um conjunto de estratégias usadas pelo grupo para garantir sua reprodução social, e ao serem transmitidas permitem que as novas gerações desenvolvam suas próprias habilidades. Trata-se do que Pietrafesa de Godoi (1999) chama de "história incorporada e recriada" e que se aproxima da noção de habitus de P. Bourdieu. O habitus para Bourdieu seria "um sistema de disposições duráveis" , que equivaleria a modos de perceber, de sentir, de fazer e de pensar, que nos levam a agir de 
uma determinada forma em uma determinada circunstância (Bourdieu 2009: 90). Como estruturas cognitivas que resultam da incorporação das estruturas objetivas do mundo, o habitus seria uma espécie de "princípio gerador de estratégias que permite aos agentes enfrentar situações imprevistas e em constante mudança” (Bourdieu e Wacquant, 1995: 91). Através da noção de habitus é possível construir uma análise da prática social como resultado de um processo, e como um produto da história, pois garante "a presença ativa de experiências passadas" que ao serem reproduzidas sob a forma de "esquemas de percepção, de pensamento e ação, tendem, mais seguramente que todas as regras e todas as normas explicitas, a garantir a conformidade das práticas e sua constância através do tempo" (Bourdieu, 2009: 90).

Nesse sentido, ao analisar as narrativas que conservam a memória social do lugar, e também da família Ramos, e são reproduzidas por diferentes gerações, é possível perceber as estruturas cognitivas que são reproduzidas nas estratégias utilizadas pelos moradores do São João, na forma de um habitus, que lhes permite continuar morando nesse tipo de ambiente. Retrata, ainda, o esforço do grupo para estabelecer os vínculos entre as gerações, e dar continuidade à memória social com a história do lugar ao longo das gerações, e impedindo que o ela entre elas seja desfeito (Connerton, 2000). Portanto, as narrativas "permitem que as pessoas processem, lembrem e transmitam conhecimentos sobre o passado" (Amado, 1996: 161) e que experiências sejam repassadas as novas gerações.

Isso aqui é uma ilha! A terra verdadeira é a de lá. A terra verdadeira mesmo, que a gente anda, é de lá, onde tem o andirobal. [Lá] é a terra da comunidade verdadeira, que era a comunidade [...] A terra era na enseada lá! Inclusive tem um canozinho que tá ai na enseada. O papai conta que aquele canozinho era no centro da mata! Era longe esse cano pra chegarem nele! Tinha onça, ninguém podia andar sozinho nessa terra que as onças rastejavam eles. E quando eles entravam lá pro centro, eles passavam por esse cano pra chegar nos lagos, pra matar pirarucu. Eles iam nesse cano só pra matar pirarucu, nem precisavam chegar nos lagos. [o pirarucu saia dos lagos] Arribava e eles faziam o curralzinho, matavam pirarucu aí nesse cano mesmo. Aí ele tava dizendo: - É verdade meu filho, esse cano aqui um dia já foi no centro e agora tá na beira da água... Por aqui eu andava com teus tios matando pirarucu. Às vezes ninguém andava só por causa das onças que rastejavam a gente aqui pela beira mesmo! E agora tá na beira do rio [Solimões]. Inclusive a terra caída tá puxando ele. Então, pelo que ele diz, a terra deveria ser lá quase daquele lado! (Sr. C. Ramos, 26 anos, comunidade de São João, novembro de 2000).

As narrativas, juntamente com a vivência empírica na paisagem, permitem que as

Iluminuras, Porto Alegre, v. 14, n. 34, p. 11-32, ago./dez. 2013 
atuais gerações se apropriem de, e também reproduzam, um conhecimento sobre o ambiente dinâmico da várzea amazônica. Esse conhecimento é o que Ingold (2000) considera como sendo a contribuição que as gerações passadas repassam para as gerações seguintes, ou seja, refere-se a um conjunto de informações que é repassado de uma geração a outra, e contem o que o autor chama de "mundo da vida e da experiência" (Ingold, 2000). Ele resulta de um processo que envolve a experiência, o desenvolvimento de habilidades e a consciência que o sujeito desenvolve enquanto habitando o mundo. É esta experiência do habitar no mundo que é transmitida nas narrativas quando se observa que elas eram proferidas enquanto as pessoas (narradores) percorriam a paisagem, e assim podiam apontar os lugares significativos, necessários para ancorar os eventos narrados. Portanto, essa estratégia reforça as formas de habitar esse ambiente, e as estratégias utilizadas para repassar às novas gerações um conhecimento sobre o ambiente, ou seja, não se trata de um conjunto de informações que são repassadas sem estar em conexão com a vida real, ou que possuam autonomia em relação ao "mundo da vida e da experiência", no sentido dado por Ingold (2010). Esse conhecimento também está expresso nas estratégias de produção econômica, no uso dos recursos naturais para sua subsistência, nas tecnologias de construção das casas, e nas diferentes formas de interagir com a natureza, de conhecer processos, ritmos e formas de existência dos vários organismos que fazem parte desse ambiente.

Esse conjunto de práticas ou modos de fazer as coisas, expressa modelos de conhecimento e de saberes, formas de classificação e de categorização do ambiente, e um sistema de representações que são historicamente reafirmadas e consolidadas ao longo das gerações, e que formam um patrimônio cultural (Gonçalves, 2005) que é conservado ao longo de várias gerações ${ }^{14}$. Conservar a memoria do lugar, como um patrimônio, permite que as várias gerações mantenham um vinculo com um lugar que persiste no tempo, e no espaço, na medida que elas podem percorrer as trilhas abertas pelos ancestrais, identificar lugares significantes para reforçar o vinculo com o grupo ancestral e com o lugar, ou seja, os lugares de memória que reforçam a memoria do lugar (Nora, 1997).

\footnotetext{
${ }^{14}$ Para Gonçalves, do ponto de vista etnográfico é possível concebermos o patrimônio enquanto uma categoria do pensamento que possui uma dimensão que está fortemente ligada à experiência, e que se opõe à visão do patrimônio como algo externo (Gonçalves 2005).
}

Iluminuras, Porto Alegre, v. 14, n. 34, p. 11-32, ago./dez. 2013 
O papai conhece isso tudo aqui. Ali, quando chega alguém conhecido dele, da época dele daqui, aí vão conversar: - Ah, compadre, tá muito diferente lá o São João!; - Ah, compadre, nunca mais fui lá no São João; - Ah, compadre, quero que o senhor veja como que tá, totalmente diferente! Aquela terra fulano de tal, lá ali, bem, não existe mais. Aquela ilha já se acabou, lá pro outro lado de lá tem duas, três ilhas. Eles chamam duas, três ilhas por causa que é uma por fora e outra por dentro que é ali onde a Elci mora; - Aí são duas, três ilhas, compadre, na frente onde era o rio mesmo. Ali, onde tapava [fechava a passagem no verão] agora tem um lago chamado Poção. Ali, onde era o Macaquinho (ilha) que entrava o motor, agora não passa mais nada! Fechou, já é lago! E aí eles ficam conversando! Aí eles se entendem. Agora, a pessoa que entra no meio [da conversa], não entende! (Sr. C. Ramos, 26 anos, comunidade de São João, outubro de 2000)

A narrativa do Sr. C. Ramos ${ }^{15}$, traduz a maneira como os moradores do São João se relacionam com o ambiente dinâmico da várzea, como percebem as transformações no lugar e nas paisagens, e lidam com a constante mobilidade de suas casas em função das mudanças provocadas pela agencia da própria natureza. Através dos relatos orais de seu pai ele consegue vislumbrar a paisagem do lugar que existiu no passado, mesmo sem ter vivenciado empiricamente esta paisagem, sem ter percorrido as trilhas e os locais onde os eventos ocorreram. E isso é possível porque foi "situado", ou "implicado", na paisagem, através de um processo que ocorre tanto pela ação, por "estar ativamente movendo-se em torno da paisagem e deixando traços nela [...] quanto através das narrativas sobre as ações que os antigos nela realizaram" (Gow, 1995: 51). Pela memória do pai ele fica sabendo que "o rio verdadeiro mesmo" corria por onde hoje está a ilha do Pão, e que nos locais onde hoje se plantam roças de mandioca, antes havia casas.

As narrativas que transmitem a história do grupo social ajudam a conservar o vinculo das gerações do presente com seus ancestrais. $\mathrm{O}$ ato de narrar eventos é uma maneira de falar das experiências passadas, uma maneira de falar dos antigos e da historia do grupo social, e perpetuar a memória sobre a história do lugar (Alencar, 2007) e se constitui em uma memória de longa duração (Eckert, 2012). A memória é "um trabalho sobre o tempo vivido" e sobre "a cultura do indivíduo", o homem adaptou o tempo a sua realidade e cada grupo social o vive à sua maneira (Bosi, 1993: 281). Mas esta memória é também um modo de atualizar e de se construir as práticas sociais (Woortmann, 1998) que são repassadas de uma geração para outra.

${ }^{15}$ Sr. C. Morais Ramos, era morador da comunidade São João, e bisneto do fundador do povoado, João Ramos. A época da entrevista Carlos era o presidente da comunidade e tinha 26 anos. Meses depois foi embora para a cidade de Tefé. A entrevista foi realizada em sua casa no dia 13 de outubro de 2000, com a presença de sua esposa. Em 2012 ele retornou para morar na comunidade.

Iluminuras, Porto Alegre, v. 14, n. 34, p. 11-32, ago./dez. 2013 
No São João as evidencias materiais do lugar antigo, da paisagem do passado, não são facilmente detectadas, apenas consegue visualiza-las quem possui as referencias toponímicas que são os lagos, os rios e as casas.

\begin{abstract}
O papai, basta dizer que os irmãos dele chamam ele de índio, porque não tem ninguém que conheça essa terra melhor do que ele! Se ele entrar aqui assim ele diz: - Vou sair em tal canto, em tal lago! Ele vai. [...] Eu trabalhava com ele aí dentro. Nós ia passando pelos lugares e ele ia me falando: - Por aqui eu já passei com teu avô. - Por aqui eu já andei com seu fulano de tal que já morreu. Aí ele me conta as histórias todas daí desse cano [que dá acesso ao lago do Pão]. Inclusive, bem na entrada do cano ele diz: - Meu filho, aqui morou um homem que vendia essas coisas, tecidos, botão, vendia aqueles negocinhos de colar; e com o tempo ele saiu daqui, abandonou a casa e se acabou tudo [...] Isso era naquela terra que fica atrás dessa ilha aqui, que essa outra ilha de lá é onde ele me disse que passava o rio. Era o rio verdadeiro mesmo. Aí ele me conta que por aí era o rio [Solimões]. (Sr. C. Ramos, 26 anos, comunidade de São João, outubro de 2000).
\end{abstract}

O narrador, através da memória do pai que contem os eventos sobre a história do lugar, consegue descrever a paisagem do passado e conhecer as transformações que ocorreram. Este conhecimento o ajuda a entender as transformações que estão ocorrendo no presente, e prever as que podem ocorrer no futuro (Alencar 2002 e 2007). Conhecer esta paisagem é importante para orientar a mobilidade espacial das famílias sobre o espaço no presente, de escolher o local para construir as casas e as roças, e prever os eventos.

A forma de percepção do ambiente dos moradores de São João, retrata uma "sintonia fina e uma sensibilização de todo o sistema perceptivo que denuncia como "o mundo dos materiais" é apreendido cognitivamente (Ingold, 2000). Para eles a natureza e as pessoas, são dotados de agencia, e atuam alterando as paisagens. Através das narrativas os mais velhos conseguem transmitir as experiências e conhecimentos sobre o ambiente, apontando os eventos responsáveis pelas transformações que ocorreram na paisagem, e este conhecimento permite as novas gerações prever as transformações futuras. Essa forma de transmissão de conhecimento torna evidente o papel constitutivo do discurso na vida social e da memoria da história desse grupo (Eckert, 2012).

A narrativa tem assim uma função integrativa, como destaca Benjamin (1985) em seu estudo sobre o papel da memória na construção da narrativa, ao afirmar que o narrador ao contar suas histórias recorre a um acervo de experiências de vida, composto tanto por suas próprias experiências como pelas experiências relatadas por outros. Para Benjamin (1985)

Iluminuras, Porto Alegre, v. 14, n. 34, p. 11-32, ago./dez. 2013 
as pessoas contam o que experimentaram, e que conservam em sua memória, e ao narrar permitem que suas experiências se tornem experiências daqueles que estão ouvindo.

\begin{abstract}
Esse ano já modificou porque essa praia não saiu mais. No ano passado, nesse tempo [mês de outubro], ela já tinha saído, ela já tava alta. Esse ano já não saiu. Acho que é porque ela acabou mais. Mas tem ano que ela sai, e no outro ano já muda pra outro canto. Ninguém sabe onde ela vai sair. A praia é uma coisa que ela sai com dois anos num canto e, quando vê, ela se acaba. Ninguém sabe pra onde ela vai. Sei que muda. Uns oito anos atrás saia uma praia, nesse tempo ainda era raso essa ressaca do Jarauazinho, não tinha aquela praia. Era bem confronte ao Norberto, donde o Saíde mora. Bem aí saia uma praia. Bem no meio mesmo. Todo mundo pegava tracajá lá. Aí, com uns dois, três anos já a praia não saiu mais. Ninguém sabe pra onde ela foi. Até agora não saiu mais. Aí já cresceu essa outra aqui embaixo já. Eu acho que ela baixa. Muitos velhos antigos já diziam que a praia, ela muda. Ela não fica só num lugar não. Também onde ela parar, ela cria uma ilha. (Sr. V. Morais, São João, novembro de 2000).
\end{abstract}

Ao falar de sua experiência de habitar o mundo da várzea, e acompanhar as transformações nas paisagens, o narrador se refere à ilha como se fosse um ser dotado vontade própria, que não se pode controlar, apenas acompanhar sua decisão. Ele precisa conhecer a linguagem da natureza, ou seja, dominar certos códigos para entender os sinais que estão sendo emitidos, e elaborar as previsões para o futuro. Por conhecer as diferentes etapas, e os vários elementos de paisagem que surgem em sequencia, que fazem parte do processo de transformação da paisagem - as praias, as ilhas, as restingas, os lagos, os paranás, as ressacas, e os vários tipos de plantas que se sucedem ao longo desse processo o narrador consegue apontar para a configuração da paisagem do futuro. Portanto, o surgimento de uma praia nova, logo após a cheia do rio, constitui o primeiro sinal de que uma transformação está se processando na paisagem.

O narrador, ao descrever as transformações na paisagem, também procura situar no tempo, e no espaço, as ações das gerações passadas, destacando os vários deslocamentos realizados pelas famílias num espaço de tempo muito curto, abrindo lugares e construindo novas paisagens.

Quando eu vim morar pra cá, aquela ilha [Macaquinho], onde é o meu terreno, era assim como essa praia aí, já tava formando ilha, era um tabuleiro ${ }^{16}$. Aí foi crescendo, foi criando aquelas tacanas, aquelas imbaúbas, aí ficou uma ilha. Aí foi o tempo que não

\footnotetext{
${ }^{16}$ Praias que surgem às margens ou no meio do rio Solimões na época do verão, e onde as gaivotas e diferentes espécies de quelônios fazem sua reprodução, construindo ninhos, fazendo a desova.
}

Iluminuras, Porto Alegre, v. 14, n. 34, p. 11-32, ago./dez. 2013 
serviu mais pra tabuleiro, aí ficou lá criando ilha, criando os matos (...). Aí a ilha cresceu, e foi o tempo que eu me casei e fui morar lá pro Jarauá, que a mamãe tinha uns gados, aí fui pra lá criar os bois dela. O nome do lugar era Vista Longe, uma costa bonita que tinha, mas já caiu tudo! Daí nós saímos e fomos pra boca do varador de um lago lá dentro do Jarauá. O varador ficava bem no nosso terreiro mesmo! [...] Aí foi o tempo que abriu também outra caída de terra. Caiu a frente da terra tudinho e chegou lá com nós. Aí nós passamos pra morar na ilhinha. Aí que apareceu um macaquinho lá, desses macaquinhos de cheiro, aí botaram já o nome da ilha de Macaquinho. Aí nós fomos pra lá. Abrimos um lugar lá, aí passemos o gado nosso pra lá e fomos morar lá. (Sr. L. Morais, São João, novembro de 2000).

Nesta narrativa, o narrador descreve as ações que ele e sua família realizaram sobre a paisagem, fazendo roças, construindo casas ou campos para a criação de gado, e também as mudanças que ocorreram na paisagem pela agência da própria natureza, que formou praias e ilhas, e destruiu as ilhas mais antigas. É o relato de sua própria mobilidade dentro, e juntamente, com a paisagem. Assim, a experiência que resulta da vivência empírica das mudanças que aconteceram no passado, e a experiência partilhada com as gerações passadas, são importantes para a construção de um conhecimento que permite fazer as previsões das mudanças que poderão acontecer no futuro. As pessoas acompanham, ano após ano, o desenvolvimento da praia, ou o seu desaparecimento, para fazer previsões sobre as mudanças que acontecerão na paisagem, e também planejar suas atividades, como a construção de uma casa ou de uma roça. Observam, escutam os sinais, interagem com a natureza para tentar prever, por exemplo, o nível da próxima cheia buscando sinais no comportamento da água, no comportamento de animais e plantas para saber se a água vai subir mais ou se vai parar, ou se vai começar a baixar, indicando o término da cheia. Portanto as percepções sobre o ambiente são resultados da experiência de habitar o mundo, que contem tanto o conhecimento acumulado ao longo das gerações quanto o desenvolvimento de certas habilidades que surgem na interação com os diferentes seres.

\section{Os rastros dos antigos: capoeiras e plantas como lugares de memória}

No São João ao mesmo tempo em que as pessoas descrevem as mudanças que ocorreram na paisagem, como o desparecimento de grandes faixas de terras e de ilhas inteiras, ou a alteração do curso do rio Solimões, elas também apontam para a permanência de alguns pontos que servem para reforçar o vínculo com o lugar formado pelos antigos. As gerações do presente realizam ações sobre uma paisagem que ainda guarda os vestígios das

Iluminuras, Porto Alegre, v. 14, n. 34, p. 11-32, ago./dez. 2013 
ações dos antepassados. As capoeiras dos antigos e as plantas que eles cultivaram mangueiras, coqueiros, abacateiros - são as ultimas evidencias concretas das ações dos antepassados, e funcionam como veículos de comunicação entre diferentes gerações, como "lugares de memória", pois demarcam as passagens da história de um outro tempo que é transmitida através de "práticas memoráveis” no sentido dado por Nora (1997: 13).

As casas não aparecem como referencial importante porque o material usado na sua construção é perecível, a madeira, a palha, e quando desfeitas não deixam vestígios. O que sinaliza o local de uma casa são as plantas, cultivadas pelos moradores, como se pode constatar na fala do Sr. L. Macário ${ }^{17}$.

Essas mangueiras era planta dos antigos, pai da Maria. Esse cacaueiro, coqueiro, também é planta deles. Aqui foi do pai dela. Depois dele morrer [...] aí o Modestino veio e tirou essa terra aqui, que tava devoluta [...] Aí tava aqui abandonado e agora já o pessoal meteram o terçado aqui e começaram a fazer a roça [...] Tem mais ou menos uns trinta e cinco anos, que eles trabalharam aqui [...] Aí abandonaram e agora o pessoal já tão trabalhando aqui de novo. Era roça de antigo! Ali pra cima tudo já foi capoeira dos antigos. Desse lado aqui tem uma ponta de terra que era roça minha, e daquele lado ali naqueles frutapãozeiro, ali morou também a minha sogra, a finada Chiquinha. Bem ali naquele lado de lá, aí tem uns cacueiros, aí tudo era plantio deles. Ali na terra que passa pr'ali assim, essa terra assim alta, que passa lá dentro, é a terra do centro. A terra onde tinha a minha roça é a segunda, onde ta a capoeira que eu trabalhava quando a minha mulher era viva. Foi antes de ir morar no Macaquinho. Lá tem umas plantas. Tinha limeira, tinha abacate, manga, mas a água matou um pouco. (Sr. L. Macário, 70 anos, São João, novembro de 2000).

À época da pesquisa as capoeiras dos antigos, tinham mais de seis décadas, e eram pontos importantes de referência tanto para situar um evento na paisagem geográfica, quanto para situar uma pessoa numa paisagem de parentesco, e para classificar os espaços socialmente construídos, ou como espaço-âncora da memória familiar, uma vez que está pautada no trabalho que constrói o lugar (Woortmann, 1990). Portanto, as capoeiras são as testemunhas de um trabalho passado, e reforçam o vínculo dos moradores do presente com a terra que foi trabalhada pelos ancestrais, e também garantem aos descendentes os direitos sobre a terra, como podemos observar na narrativa da Sra. G. Castilho, a seguir ${ }^{18}$.

\footnotetext{
${ }^{17}$ Sr. L. Macário de Morais, um dos moradores mais antigos da comunidade São João. Na data em que foi realizada a entrevista, 19 novembro de 2000, ele tinha 70 anos. A entrevista foi realizada na sua roça, em uma capoeira aberta pelos antigos moradores.

${ }^{18}$ A Sra. G. Castilho é moradora da comunidade São João, filha de uma das moradoras mais antigas do lugar, mas que não pertencia a família fundadora do povoado. Na época da entrevista ela tinha 52 anos. A entrevista foi realizada em sua roça no dia 09 de novembro de 2000.
}

Iluminuras, Porto Alegre, v. 14, n. 34, p. 11-32, ago./dez. 2013 
Tudo isso era capoeira desse pessoal, da mãe desse meu marido. Ela morava aí no São João, e fazia roça por aqui. Aí, depois que eu me casei com esse meu marido, aí nós viemos ainda fazer roça pra cá com a velhinha mãe dele (...) E por aqui o pessoal antigo andava. A mãe dele cansou de trabalhar por aqui em roça. Tinha muitas plantas. Era aquelas roças tudo grande. Por aí tem mangueira, por aí tem açaizeiro, tem bacabeira, tudo planta deles [...] Isso aí era planta da mãe daquele Macário, ali onde tem aquela árvore de açaí e aquela mangueira. Aqui é que é planta da comadre Dorinha. Aqui foi onde ela roçou primeiro [...] Ali onde tá aquela capoeira é planta da mulher do Dilau, mãe do Antônio. Aqui pra dentro tem uma da finada Mariquinha, a mãe do meu marido. Era onde eu vinha plantar mais ela. Pr'ali daquele lado tinha uma roça do compadre Macário com a comadre Maria Dute, antes daquela alagação grande. Depois daquela alagação grande ele foi embora daqui. (Sra. G. Castilho, 52 anos, São João, novembro de 2000).

Ao plantarem uma roça na capoeira de um antepassado as pessoas estabelecem um contato social implícito no tempo, que ocorre pela sucessão do trabalho que é realizado nas mesmas capoeiras. Portanto, considerando-se que "o trabalho deixa marcas no espaço, marcando o tempo" (Woortmann, 1998: 147), o (re) trabalhar a terra é também um modo de (re) afirmar as relações de parentesco, e o vinculo com os fundadores do lugar. Com a destruição das paisagens, das terras que abrigavam o lugar ancestral, as famílias que permanecem no local lutam constantemente contra a perda de suas referencias simbólicas e afetivas com esse lugar. O retrabalhar a terra, e o ato de narrar a historia do grupo social, marcada por lembranças e esquecimentos é uma forma de dar continuidade à memória do grupo social e do lugar de pertença (Eckert, 2012), que se traduz no esforço de dar continuidade no tempo as imagens que compõe as paisagens da várzea, e do lugar ancestral, diante das perdas e das transformações que observam no seu mundo.

Em 2011 ao retornar ao São João pude constatar que as áreas de terras mais altas estavam reduzidas e que as novas gerações estavam construindo suas casas sobre as capoeiras dos antigos, ou em locais onde antes era a casa de um antigo morador. Assim, eles estavam agindo sobre os últimos vestígios das ações dos que viveram no passado, ocupando as ultimas fronteiras de um território construído pelos ancestrais.

\section{Conclusão}

Procurei mostrar neste artigo as estratégias que as famílias do São João adotam, há quase um século, para manter o vinculo com o lugar aberto pelos ancestrais, onde a destruição das terras sob a ação das correntezas do rio Solimões altera a paisagem e 
provoca a constante mobilidade das casas. Embora não exista mais a terra onde foram construídas as primeiras casas e o campo de gado que sinalizavam a origem do lugar, as pessoas ainda mantêm uma relação com este lugar inicial, que é reforçada tanto pelos laços de parentesco que unem os moradores do lugar, quanto pela existência de certos elementos da paisagem que testemunham esse pertencimento, como as capoeiras e as plantas cultivadas pelos antepassados.

Através das narrativas os moradores expressam o modo como interagem com o ambiente peculiar da várzea, e reconstroem no tempo o lugar que foi constituído e ordenado socialmente por uma família. As narrativas buscam localizar ancoras da memória que ajudem situar os moradores do presente num lugar e numa paisagem do passado que não é identificada no presente, articulando a representação do lugar do passado e a percepção do lugar que é encontrado no presente, traduz o esforço de reconstruir a paisagem do lugar do passado, procurando situá-la num tempo que é estrutural, o tempo dos antigos.

A narrativa sobre transformação do espaço em lugar, que é também a descrição do processo de destruição das paisagens e do próprio lugar, contem experiências pessoais e práxis coletivas que traduzem formas particulares de interação com o ambiente, e com uma paisagem que está continuamente sendo transformada tanto pela agencia humana, quanto pela agência da própria natureza. O esforço de conservar a memória do lugar esbarra na dificuldade de encontrar lugares de memoria, uma vez que a paisagem é desfeita a cada ano, e certas referencias usadas para situar as pessoas na paisagem e no lugar ancestral - o cemitério, as casas dos moradores mais velhos, o campo de futebol, a escola e as árvores que sinalizavam sua localização, ou a entrada de um lago - desapareceram junto com a terra que caiu. Mas para as gerações do presente esse lugar tem continuidade no presente, concretizado nas capoeiras, e nos descendentes dos fundadores do lugar, que servem como referencial para a construção da identidade deste grupo social, e reforçavam o pertencimento a um grupo de parentesco, e a um lugar.

Assim, as histórias sobre as paisagens e o lugar que são narradas pelos mais velhos, funcionam como ancoras da memoria do lugar, e demonstram o esforço de retraçar no espaço, e presentificar no tempo, as paisagens ancestrais, os fatos e eventos que formam o patrimônio cultural do grupo. Assim, com a destruição das paisagens, consideradas como uma dimensão do mundo material, e do lugar praticado, as famílias que permanecem no 
São João travam uma luta permanente contra a perda de suas referencias identitárias, e dos vínculos com o lugar de pertença. Nesse contexto as narrativas são meios utilizados para dar continuidade a uma herança, que é a história da origem do grupo social, da famílias Ramos, e do lugar de pertença.

Com a redução do espaço físico da ilha, suas casas já estão próximas as capoeiras dos moradores das comunidades vizinhas, em um futuro próximo, não poderão mais fazer o deslocamento de suas casas seguindo a mesma direção - do fluxo do rio - que historicamente lhes permitiu manter as mesmas referencias espaciais que reforçavam a paisagem do passado, e remetiam ao momento de fundação do lugar e do grupo social. Uma alternativa encontrada pelas novas gerações é construir suas roças nas novas ilhas que se formaram nas ultimas décadas, na margem oposta do rio Solimões, num movimento que segue o sentido contrário ao que seguiam até o momento. Ao assim proceder, estão deixando seus rastros para serem trilhados pelas futuras gerações. Mas considerando-se que essas terras serão também destruídas pelas fortes correntezas do rio Solimões, é necessário manter o vínculo com os antepassados, com o lugar onde os ancestrais começaram a inscrever sua história e que deu origem ao grupo social, como o lugar que serve de suporte para a afirmação de uma identidade deste grupo social.

O fato de algumas famílias optarem por morar em casas flutuantes é uma demonstração clara de que o sentido de pertencimento ao lugar está relacionado, principalmente, à continuidade dos laços de parentesco. Portanto, para que as novas gerações consigam conhecer a história das ações dos antigos e, dessa forma, adquirir o vínculo com o lugar, ela dependerá do seu grupo de parentesco, em especial, da memória social, das experiências sobre o habitar esse ambiente, o lugar, que este grupo vem partilhando ao longo de varias gerações, que contem a sua história, e que precisa ser reproduzida nas narrativas orais. Mas a migração, e a morte, daqueles que são os detentores da memória sobre a origem do lugar, do grupo social e também da historia do próprio ambiente, surge como uma ameaça à reprodução desta memória.

Ao se interromper a cadeia de transmissão da narrativa sobre esse momento fundante da história do grupo social, ou sobre as ações dos antepassados que construíram um lugar, um território, perdem-se os vínculos que unem as gerações do passado com as gerações do presente, perde-se um patrimônio cultural importante para a continuidade do grupo.

Iluminuras, Porto Alegre, v. 14, n. 34, p. 11-32, ago./dez. 2013 
Portanto, as perdas são tanto materiais, a terra que deixa de existir em sua concretude, como também simbólicas, a perda dos laços afetivos com um grupo social e com um lugar, e o sentido da história do grupo e do próprio ambiente.

\section{Referências}

ALENCAR, Edna F. Memórias de Mamirauá. Belém; IDSM/MCT. 2010.

Paisagens da memória: narrativa oral, paisagem e memória social no processo de construção da identidade. Teoria \& Pesquisa. V. XVI, p.43 - 56, 2007.

Terra caída: encante, lugares e identidades. Brasília, 2002. 245p. Tese de doutorado em Antropologia, Universidade de Brasília, Dep. de Antropologia.

ALENCAR, Edna F.; SOUSA, I. S. Mapeamento territorial e diagnóstico socioambiental de comunidades rurais situadas nas RDS Amanã e Mamirauá, Am. Relatório Técnico. Projeto de Pesquisa. Tefé, 2012.

AUGÉ, Marc. Lugar e não lugares. Introdução a uma antropologia da supermodernidade. Campinas: Papirus Editora. 2012.

AYRES, José Márcio, MOURA, Edila. F., LIMA-AYRES, Deborah de M. "Estação Ecológica Mamirauá: o desafio de preservar a várzea na Amazônia". In: Trópico em Movimento: alternativas contra a pobreza e a destruição ambiental no trópico úmido. Belém: UFPa, POEMA. 1994.

AYRES, José Márcio. As matas de várzea de Mamirauá. Sociedade Civil Mamirauá/SCMMCT/CNPq. Brasília,1996

AMADO, Janaina, \& FERREIRA, Marieta de M., Usos \& Abusos da história oral. Rio de Janeiro: Editora da Fundação Getulio Vargas, 1996.

BACHELARD, Gaston. A poética do espaço. Martins Fontes, São Paulo, 1993.

BATES, Henry W. Um naturalista no rio Amazonas. Belo Horizonte : Itatiaia; São Paulo: Editora da Universidade de São Paulo. 1989.

BENJAMIN, Walter. O Narrador - considerações sobre a obra de Nikolai Leskov. In: Magia e técnica, arte e política. São Paulo: Brasiliense, 1985.

BOSI, Ecléa. Memória e Sociedade: Lembranças de Velhos. São Paulo: Companhia das Letras, 1994.

BOURDIEU, Pierre. O Senso Prático. Trad. Maria Ferreira. Petrópolis, RJ: Vozes. 2009. p. 470

BOURDIEU, Pierre e WACQUANT, Loic J. D. Respuestas: por una antropología reflexiva. Trad. Hélène Levesque Dion. Mexico, Editorial Grijalbo. 1995.

CAIUBY NOVAES, Sylvia. Paisagem Bororo: de terra a território. In (Orgs.) NIEMEYER, Ana M.

Iluminuras, Porto Alegre, v. 14, n. 34, p. 11-32, ago./dez. 2013 
de, e P. DE GODÓI, Emília. “Além dos territórios: para um diálogo entre a etnologia indígena, os estudos rurais e os estudos urbanos”. Campinas, São Paulo:Mercado de Letras, 1998.

CONNERTON, Paul. How Societies Remember. Cambridge: Cambridge University Press. 1989.

CRUMLEY, Carole L. Historical ecology: a multidimensional ecological orientation. In Historical Ecology: cultural knowledge and changing landscape (Ed. by Carole L. Crumley). School of American Research Press, Santa Fé, New Mexico, 1996.

DELORIA JR., Vine, "Thinking in time and space". In: God is Red: A native view of religion. Golden, Colorado:Fulcrum Publishing. 1994

ECKERT, Cornelia. Memória e trabalho: etnografia da duração de uma comunidade de mineiros de carvão (La Grand-Combe, França). Curitiba: Appris, 2012. 280 p.

GEERTZ, Cliford. O saber local: novos ensaios em antropologia interpretativa. Petrópolis: Vozes. 1997.

GONÇALVES, José Reginaldo S. Ressonância, materialidade e subjetividade: as culturas como patrimônios. Horizontes Antropológicos, Porto Alegre, ano 11, n. 23, p. 15-36, jan/jun 2005.

GOW, Peter. Land, Paper and People in Western Amazônia, in Eric HIRSCH and Michael O'HANLON (eds) The Anthropology of Landscape: perspective on Place and Space. Claredon Press - Oxford University Press. 1995.

HALBWACHS, Maurice. 1990. A memória coletiva. São Paulo: Vértice Editora.

INGOLD, Tim. The perception of the environment: essas in livelihood, dwelling anda skil. London:Routledge, 2000.

LIMA, Deborah de M. \& ALENCAR, Edna F. Histórico da ocupação humana e mobilidade geográfica de assentamentos na várzea do médio Solimões, AM. In Haroldo Torres e Heloisa Costa (orgs.) População e Meio Ambiente: debates e desafios. São Paulo: Editora SENAC São Paulo, 2000.

LIMA, Deborah de M. \& ALENCAR, Edna F. A Lembrança da História: identidade, ambiente e memória social na várzea do médio Solimões, AM. Edition Lusotopie, Paris, France, 2001.

LIMA-AYRES, Deborah. The Social Category Caboclo: History, Social Organization, Identity and Outsider's Social Classification of the Rural Population of an Amazonian Region (the middle Solimões). Dissertação de Doutorado, Universidade de Cambridge, Inglaterra. 1992.

MAUSS, Marcel. Sociologia e Antropologia .Vol II. São Paulo, EDUSP. 1974.

NORA, Pierre. Entre memória e história: a problemática dos lugares. Projeto História, São Paulo, n.10, dez. 1993, p.7-28.

PIETRAFESA DE GODÓI, Emilia. O trabalho da memória: cotidiano e historia no sertão do Piaui. Campinas: Editora da UNICAMP, 1999. 
ROSALDO, Renato, 1980. Ilongot Headhunting 1883-1974: a study in society and history. Stanford University Press, Stanford, California.

RICHARD, Nelly. Políticas da memória e técnicas do esquecimento. IN "Narrativas da Modernidade” (MIRANDA, Wander M. Org.). Belo Horizonte: Autêntica. 1999.

SCHAMA, Simon. Paisagem e Memória. São Paulo: Companhia das Letras, 1996.

SCM/CNPq/MCT-Mamirauá: Plano de Manejo. Brasília, SCM/CNPq/MCT. Manaus: IPAAM. 1996. 96 p.

SILVEIRA, Flavio L. A paisagem como fenômeno complexo, reflexões sobre um tema interdisciplinar. IN: SILVEIRA \& CANCELA (Orgs.). Paisagem e Cultura: dinâmica do patrimônio e da memoria na atualidade. Belém. EDUFPA, 2009. 243p.

STEIL, Carlos A. \& CARVALHO, Isabel C. de M. Diferentes aportes no ãmbito da antropología fenomenológica: diálogos com Tim Ingold. IN: STEIL, Carlos A. \& CARVALHO, Isabel C. de M. (Orgs.) Cultura, Percepção e Ambiente: diálogos com Tim Ingold. São Paulo: Editora Terceiro Nome, 2012.

TUAN, Yi-Fu. Espaço e lugar: a perspectiva da experiência. Difel, São Paulo, 1983.

WOORTMANN, Ellen F. Família, mulher e meio ambiente no seringal. In "Além dos territórios: para um diálogo entre a etnologia indígena, os estudos rurais e os estudos urbanos" (Orgs). NIEMEYER, Ana Maria de, e PIETRAFESA DE GODÓI, Emília) Campinas, São Paulo:Mercado de Letras. 1998.

WOORTMANN, Ellen F. A Árvore da Memória. UNB. Departamento de Antropologia. Série Antropologia $\mathrm{n}^{\circ}$ 159. 1990.

Recebido em: 10/09/2013

Aprovado em: 05/10/2013 